\title{
Zoneamento agroclimático de café robusta no Estado do Paraná e impactos das mudanças climáticas
}

\section{Agroclimatic zoning of robusta coffee in the State of Paraná and impacts of climate change}

\author{
Giselly Aparecida Andrade ${ }^{1 *}$; Wilian da Silva Ricce ${ }^{2}$; Paulo Henrique Caramori ${ }^{3}$; \\ Geovanna Cristina Zaro ${ }^{4}$; Cristiane de Conti Medina ${ }^{5}$
}

\begin{abstract}
Resumo
O objetivo do trabalho foi realizar o zoneamento agroclimático de café robusta (Coffea canephora Pierre ex Froehner) no estado do Paraná e verificar as alterações causadas neste, pelo incremento de temperatura, provocado pelo aquecimento global, conforme prognósticos para os próximos 100 anos divulgados pelo IPCC (Intergovernmental Panel on Climate Change). Uma alternativa para manter a produção cafeeira no estado do Paraná poderá ser a introdução do café robusta, originário da África, adaptado a regiões com temperatura média anual entre 22 e $26^{\circ} \mathrm{C}$. Foi utilizado o banco de dados climáticos históricos do IAPAR (Instituto Agronômico do Paraná) e consideradas aptas ao cultivo as regiões que se enquadraram dentro dos seguintes critérios: risco anual de ocorrência de geadas inferior a $25 \%$, temperatura média anual entre 22 e $26^{\circ} \mathrm{C}$ e deficiência hídrica anual inferior a $150 \mathrm{~mm}$. Os mapas foram gerados sobre a base Shuttle Radar Topography Mission (SRTM) e cruzados no ambiente de Sistema de Informação Geográfica (SIG), gerando os mapas do zoneamento agroclimático do Coffea canephora para o clima atual e para os cenários de mudanças climáticas com o acréscimo de 1,8 e $4^{\circ} \mathrm{C}$ na temperatura média. $\mathrm{O}$ zoneamento para o clima atual indicou que partes das regiões noroeste e oeste são aptas ao cultivo. Sob cenários de mudanças climáticas, considerando o regime de precipitação inalterado, a área apta ao cultivo se amplia, justificando estudos sobre esta espécie no estado do Paraná. Palavras-chave: Coffea canephora, aquecimento global, temperatura
\end{abstract}

\begin{abstract}
The aim of the study was the agroclimatic zoning of robusta coffee (Coffea canephora Pierre ex Froehner) in the state of Paraná, and to verify changes caused by temperature rise related to global warming, as predictions for the next 100 years reported by the IPCC (Intergovernmental Panel on Climate Change). An alternative to keep coffee production in the state of Paraná will be the introduction of robusta coffee, original from Africa, adapted to areas with annual mean temperatures between 22 and $26^{\circ} \mathrm{C}$. We used the historical weather database from IAPAR (Agronomic Institute of Paraná) and considered as apt for cropping the areas within the following conditions: risk of annual frost lower than $25 \%$ of probability, annual mean temperature between 22 and $26{ }^{\circ} \mathrm{C}$, and annual water deficiency below $150 \mathrm{~mm}$. The spatial analyzes were based on the Shuttle Radar Topography Mission (SRTM) and crossed into the environment of a Geographic Information System (GIS), generating maps of the agroclimatic zoning of Coffea canephora for the current climate and scenarios of climate change with
\end{abstract}

\footnotetext{
${ }^{1}$ Eng $^{\mathrm{a}} \mathrm{Agr}^{\mathrm{a}}$, Dr ${ }^{\mathrm{a}}$ Agente de Ciência e Tecnologia, Instituto Agronômico do Paraná, IAPAR. Londrina, PR. E-mail: giselly@iapar.br

${ }^{2}$ Eng $^{\circ}$ Agr $^{\circ}$, Dr. Pesquisador da Agroconsult/IAPAR, Londrina, PR. E-mail: wilianricce@gmail.com

${ }^{3}$ Eng $^{\circ}$ Agr $^{\circ}$, Dr. Pesquisador do IAPAR, Londrina, PR. E-mail: caramori@iapar.br

${ }^{4}$ Bióloga, Mestranda em Bioenergia, Universidade Estadual de Londrina, UEL, Londrina, PR. E-mail: geoczaro@gmail.com

${ }^{5}$ Eng $^{\mathrm{a}}$ Agr $^{\mathrm{a}}$, Prof $^{\mathrm{a}}$ Dr $^{\mathrm{a}}$ do Dept ${ }^{\mathrm{o}}$ de Agronomia, UEL, Londrina, PR. E-mail: medina@uel.br

* Autor para correspondência
} 
the addition of 1.8 and $4{ }^{\circ} \mathrm{C}$ in the mean temperature. The zoning for the current weather indicated that parts of northwestern and western regions of Paraná are suitable for cultivation. Under climate change scenarios, considering the rainfall regime unchanged, the area suitable for cultivation expands, justifying studies on this species in the state of Paraná.

Key words: Coffea canephora, global warming, temperature

\section{Introdução}

Tradicionalmente, a espécie cafeeira cultivada no estado do Paraná é a Coffea arabica L. (café arábica) por apresentar boa adaptação e melhor qualidade de bebida. Porém, de acordo com previsões do IPCC (2007), com o aquecimento global, a temperatura média do planeta pode sofrer acréscimos entre $1,8^{\circ} \mathrm{C}$ (cenário mais otimista $\mathrm{B} 1$ ) e $4^{\circ} \mathrm{C}$ (cenário mais pessimista A1F1). Caso isso se confirme, considerando o nível tecnológico atual haveria impactos negativos nas áreas tradicionais de cultivo do café arábica. Assad et al. (2004) analisando o impacto de aquecimentos de $1^{\circ} \mathrm{C}, 3^{\circ} \mathrm{C}$ e $5,8^{\circ} \mathrm{C}$ sobre Coffea arabica, com base nas previsões do relatório do IPCC (2001), concluíram que a área produtiva do Paraná se deslocaria para o sul do estado. No pior cenário as áreas aptas para o cafeeiro sofreriam redução de $25,2 \%$. O aumento previsto de chuvas ainda causaria problemas na qualidade da bebida.

Uma alternativa para a cafeicultura da região norte paranaense seria a introdução do café Robusta (Coffea canephora Pierre ex Froehner), que é originária da região da Guiné à República Democrática do Congo, na costa oeste do continente africano. No Brasil é cultivado em regiões com menor altitude, normalmente abaixo de 500 metros e com temperaturas mais elevadas, com média anual entre $22^{\circ}$ e $26^{\circ} \mathrm{C}$. Matiello (1991) estabeleceu os parâmetros técnicos para o zoneamento climático da cultura do café robusta, criando as classes conforme os limites térmicos: de 22 a $26^{\circ} \mathrm{C}$ (apta); 21 a $22^{\circ} \mathrm{C}$ (restrita) e $<21^{\circ} \mathrm{C}$ (inapta), e de deficiência hídrica: $<200$ (apta); 200 a 400 (restrita) e > $400 \mathrm{~mm}$ (inapta).

Embora mais produtivo que o $C$. arabica, o $C$. canephora é mais sensível às temperaturas baixas e aos ventos intensos que podem ocorrer em alguns períodos do ano, sendo necessária a utilização de quebra-ventos a fim de minimizar os danos à cultura (BLISKA et al., 2008). Os ventos e as altas temperaturas são os maiores agentes de desidratação, porque intensificam a evapotranspiração, agravando, desta maneira, os efeitos da seca (VESCOVE; TURCO, 2005). As longas estiagens diminuem mais a produtividade das lavouras não-irrigadas desta espécie, comparadas com cultivares de café arábica (BLISKA et al., 2008).

Além das condições meteorológicas durante o crescimento e o desenvolvimento da cultura do café, as características agroclimáticas das regiões produtoras podem influenciar diferentemente na produtividade final da cultura (EVANGELISTA; CARVALHO; SEDIYAMA, 2002). O zoneamento agrícola constitui uma tarefa de fundamental importância na organização dos programas de trabalho e suporte do planejamento da agricultura. O conhecimento das condições climáticas de determinada região é de extrema importância para a cultura do café, visto que a delimitação das regiões climaticamente homogêneas pode estabelecer os indicadores do meio físico e biológico para a região, além de identificar áreas de condições homogêneas de atividades e dos recursos naturais nela existentes (SANTOS, 1999).

Diante do exposto, os objetivos do trabalho foram avaliar a possibilidade do cultivo de Coffea canephora no estado do Paraná, identificando, com base em séries históricas de dados climatológicos as regiões aptas ao cultivo, além de verificar as modificações no zoneamento agroclimático desta cultura, induzidas pelos aumentos da temperatura previstos nos cenários de mudanças climáticas para os próximos 100 anos. 


\section{Material e Métodos}

Para a elaboração do zoneamento agroclimático da cultura do $C$. canephora, no Paraná, para os cenários atual e os dois cenários de mudanças climáticas previstos pelo IPCC (2007), considerando acréscimos de $1,8^{\circ} \mathrm{C}$ e $4^{\circ} \mathrm{C}$, foram analisados os seguintes parâmetros:

1) Risco de ocorrência de geadas: com base na análise das séries históricas de temperatura mínima do ar no abrigo da rede de 32 estações meteorológicas do IAPAR (Tabela 1), foram determinados os riscos de ocorrência de geadas ao nível da estação. Os dados observados de temperatura mínima de abrigo menores que
$1{ }^{\circ} \mathrm{C}$ (GRODZKI et al., 1996) foram ajustados à distribuição de extremos, seguindo procedimento descrito por Assis, Arruda e Pereira (1996). Obtevese uma equação de regressão entre as probabilidades de geada com base na latitude, longitude e altitude de cada estação: Risco de Geada de $1{ }^{\circ} \mathrm{C}=100$ * $(-2,2102078061741+-0,208673345720162 *$ [latitude] $+0,0502531494198704 *$ [longitude] $+0,000379551070181778 *$ [altitude]), e foram gerados mapas de temperatura mínima para todo o estado sobre a base SRTM 90m, utilizando o software Spring 5.1. As classes de aptidão formadas para cultivo do cafeeiro, de acordo com a probabilidade de geada, foram as seguintes:

Tabela 1. Estações meteorológicas do IAPAR, indicando o ano em que se iniciaram as coletas de dados, que foram atualizadas até o ano de 2009.

\begin{tabular}{|c|c|c|c|c|c|}
\hline & Estação & Latitude & Longitude & Altitude & Início \\
\hline 1 & Antonina & $-25^{\circ} 13^{\prime}$ & $-48^{\circ} 48^{\prime}$ & $60 \mathrm{~m}$ & 1977 \\
\hline 2 & Apucarana & $-23^{\circ} 30^{\prime}$ & $-51^{\circ} 32^{\prime}$ & $746 \mathrm{~m}$ & 1964 \\
\hline 3 & Bandeirantes & $-23^{\circ} 6^{\prime}$ & $-50^{\circ} 21^{\prime}$ & $440 \mathrm{~m}$ & 1974 \\
\hline 4 & Bela Vista do Paraíso & $-22^{\circ} 57^{\prime}$ & $-51^{\circ} 12^{\prime}$ & $600 \mathrm{~m}$ & 1971 \\
\hline 5 & Cambará & $-23^{\circ} 0$ & $-50^{\circ} 2^{\prime}$ & $450 \mathrm{~m}$ & 1957 \\
\hline 6 & Cândido de Abreu & $-24^{\circ} 38^{\prime}$ & $-51^{\circ} 15^{\prime}$ & $645 \mathrm{~m}$ & 1988 \\
\hline 7 & Cascavel & $-24^{\circ} 56^{\prime}$ & $-53^{\circ} 26^{\prime}$ & $760 \mathrm{~m}$ & 1972 \\
\hline 8 & Cerro Azul & $-24^{\circ} 49^{\prime}$ & $-49^{\circ} 15^{\prime}$ & $360 \mathrm{~m}$ & 1972 \\
\hline 9 & Cianorte & $-23^{\circ} 40^{\prime}$ & $-52^{\circ} 35^{\prime}$ & $530 \mathrm{~m}$ & 1971 \\
\hline 10 & Clevelândia & $-26^{\circ} 25^{\prime}$ & $-52^{\circ} 21^{\prime}$ & $930 \mathrm{~m}$ & 1973 \\
\hline 11 & Fernandes Pinheiro & $-25^{\circ} 27^{\prime}$ & $-50^{\circ} 35^{\prime}$ & $893 \mathrm{~m}$ & 1963 \\
\hline 12 & Francisco Beltrão & $-26^{\circ} 5^{\prime}$ & $-53^{\circ} 4^{\prime}$ & $650 \mathrm{~m}$ & 1973 \\
\hline 13 & Guarapuava & $-25^{\circ} 21^{\prime}$ & $-51^{\circ} 30^{\prime}$ & $1058 \mathrm{~m}$ & 1964 \\
\hline 14 & Guaraquecaba & $-25^{\circ} 16^{\prime}$ & $-48^{\circ} 32^{\prime}$ & $40 \mathrm{~m}$ & 1977 \\
\hline 15 & Ibiporã & $-23^{\circ} 16^{\prime}$ & $-51^{\circ} 1^{\prime}$ & $484 \mathrm{~m}$ & 1971 \\
\hline 16 & Joaquim Távora & $-23^{\circ} 30^{\prime}$ & $-49^{\circ} 57^{\prime}$ & $512 \mathrm{~m}$ & 1971 \\
\hline & Lapa & $-25^{\circ} 47^{\prime}$ & $-49^{\circ} 46^{\prime}$ & $910 \mathrm{~m}$ & 1988 \\
\hline 18 & Laranjeiras Do Sul & $-25^{\circ} 25^{\prime}$ & $-52^{\circ} 25^{\prime}$ & $880 \mathrm{~m}$ & 1973 \\
\hline & Londrina & $-23^{\circ} 22^{\prime}$ & $-51^{\circ} 10^{\prime}$ & $585 \mathrm{~m}$ & 1976 \\
\hline & Morretes & $-25^{\circ} 30^{\prime}$ & $-48^{\circ} 49^{\prime}$ & $59 \mathrm{~m}$ & 1966 \\
\hline & Nova Cantu & $-24^{\circ} 40^{\prime}$ & $-52^{\circ} 34^{\prime}$ & $540 \mathrm{~m}$ & 1976 \\
\hline & Palmas & $-26^{\circ} 29^{\prime}$ & $-51^{\circ} 59^{\prime}$ & $1100 \mathrm{~m}$ & 1978 \\
\hline & Palotina & $-24^{\circ} 18^{\prime}$ & $-53^{\circ} 55^{\prime}$ & $310 \mathrm{~m}$ & 1972 \\
\hline & Paranavaí & $-23^{\circ} 5^{\prime}$ & $-52^{\circ} 26^{\prime}$ & $480 \mathrm{~m}$ & 1974 \\
\hline
\end{tabular}


continuação

\begin{tabular}{|c|c|c|c|c|c|}
\hline 25 & Pato Branco & $-26^{\circ} 7$ & $-52^{\circ} 41^{\prime}$ & $700 \mathrm{~m}$ & 1979 \\
\hline 26 & Pinhais & $-25^{\circ} 25^{\prime}$ & $-49^{\circ} 8^{\prime}$ & $930 \mathrm{~m}$ & 1970 \\
\hline 27 & Planalto & $-25^{\circ} 42^{\prime}$ & $-53^{\circ} 47^{\prime}$ & $400 \mathrm{~m}$ & 1973 \\
\hline 28 & Ponta Grossa & $-25^{\circ} 13^{\prime}$ & $-50^{\circ} 1^{\prime}$ & $880 \mathrm{~m}$ & 1954 \\
\hline 29 & Quedas do Iguaçu & $-25^{\circ} 31^{\prime}$ & $-53^{\circ} 1^{\prime}$ & $513 \mathrm{~m}$ & 1972 \\
\hline 30 & São Miguel do Iguaçu & $-25^{\circ} 26^{\prime}$ & $-54^{\circ} 22^{\prime}$ & $260 \mathrm{~m}$ & 1982 \\
\hline 31 & Telêmaco Borba & $-24^{\circ} 20^{\prime}$ & $-50^{\circ} 37^{\prime}$ & $768 \mathrm{~m}$ & 1971 \\
\hline 32 & Umuarama & $-23^{\circ} 44^{\prime}$ & $-53^{\circ} 17^{\prime}$ & $480 \mathrm{~m}$ & 1971 \\
\hline
\end{tabular}

Fonte: Elaboração dos autores.

Aptas: regiões com risco inferior a $25 \%$;

Marginais: regiões com risco entre 25 e 35\%;

Inaptas: regiões com risco superior a $35 \%$.

2) Aptidão térmica: com base na temperatura média diária compensada foram determinadas as temperaturas médias anuais e efetuou-se a correlação dos valores pontuais com altitude, latitude e longitude: TMED_ANUAL = $(21,3350423168058+0,7865477794275370 *$ [latitude] $0,4148342047678950 *$ [longitude] $0,00534079755394762 *$ [altitude]), para a geração de um mapa com isolinhas de temperatura média em intervalos de $1^{\circ} \mathrm{C}$. As seguintes classes de aptidão térmica foram utilizadas (MATIELLO, 1991):

Aptas: áreas com temperatura média entre $22 \mathrm{e}$ $26^{\circ} \mathrm{C}$;

Marginais: áreas com temperatura média entre 21 e $22^{\circ} \mathrm{C}$ ou entre 26 e $27^{\circ} \mathrm{C}$;

Inaptas: áreas com temperatura média inferior a $21^{\circ} \mathrm{C}$ ou superiores a $27^{\circ} \mathrm{C}$.

3) Deficiência hídrica: foi utilizado o método de balanço hídrico normal de Thornthwaite e Mather (1955), com uma capacidade de água disponível no solo de $125 \mathrm{~mm}$, com base em análises anteriormente realizadas para a cultura do café (CAMARGO, 1977). Os resultados obtidos foram interpolados no software Spring 5.1, gerando-se os mapas de deficiência anual. As classes de deficiência hídrica anual adotadas, de acordo com Matiello (1991), foram as seguintes:
Aptas: regiões com deficiência hídrica anual igual ou menor que $200 \mathrm{~mm}$;

Inaptas: regiões com deficiência hídrica anual superior a $200 \mathrm{~mm}$.

Os mapas de risco de geadas, aptidão térmica e deficiência hídrica foram cruzados no ambiente SIG, gerando-se mapas do zoneamento de Coffea canephora para o clima atual e para os cenários de aquecimento de $1,8^{\circ} \mathrm{C}$ e $4^{\circ} \mathrm{C}$.

\section{Resultados e Discussão}

De acordo com os dados de balanço hídrico (Figura 1), atualmente não há restrição por deficiência hídrica no estado. Quando calculados os balanços hídricos de cada estação, com acréscimo de $1,8^{\circ} \mathrm{C}$ e $4^{\circ} \mathrm{C}$, a maior deficiência foi de $107,2 \mathrm{~mm}$, na estação localizada em Bandeirantes, que ainda é aceitável para o cultivo do café (Figura 1). Assim, este não foi considerado um fator limitante, já que a previsão do IPCC (2007) é que, além do acréscimo na temperatura, ainda ocorra um aumento de, aproximadamente, $15 \%$ na precipitação.

O zoneamento agroclimático para a cultura do C. canephora no estado do Paraná no cenário atual (Figura 2) mostra que somente as regiões noroeste e parte da região oeste e norte estão aptas ao cultivo do café robusta. Tais regiões apresentam valores de temperatura entre 22 e $23{ }^{\circ} \mathrm{C}$ (Figura 3), baixo risco de geadas (Figura 4) e balanço hídrico favorável. Nas áreas marginais, as temperaturas médias não 
são ideais, havendo risco de geadas. Portanto, a escolha do local para a implantação do cafezal deve ser mais criteriosa, evitando o plantio em baixadas e fundos de vale e selecionando áreas com exposição à face norte, que recebem maior quantidade de radiação durante o inverno. Além disso, recomendase adotar as medidas de proteção das lavouras em formação em caso de alerta de geadas, como o enterrio das mudas e o chegamento de terra no caule (CARAMORI et al., 2000).

Para a espécie C. arabica, Caramori et al. (2001), zonearam os riscos climáticos no estado do Paraná, definindo uma área com risco máximo de uma geada a cada quatro anos como macroclimaticamente apta e uma área de transição, com risco máximo de geadas de até um evento a cada três a quatro anos, onde pode haver microclimas favoráveis ao cultivo.

Figura 1. Deficiência hídrica média para o estado do Paraná, nas condições atuais e com acréscimo de $1,8^{\circ} \mathrm{C}$ e $4^{\circ} \mathrm{C}$ na temperatura média.

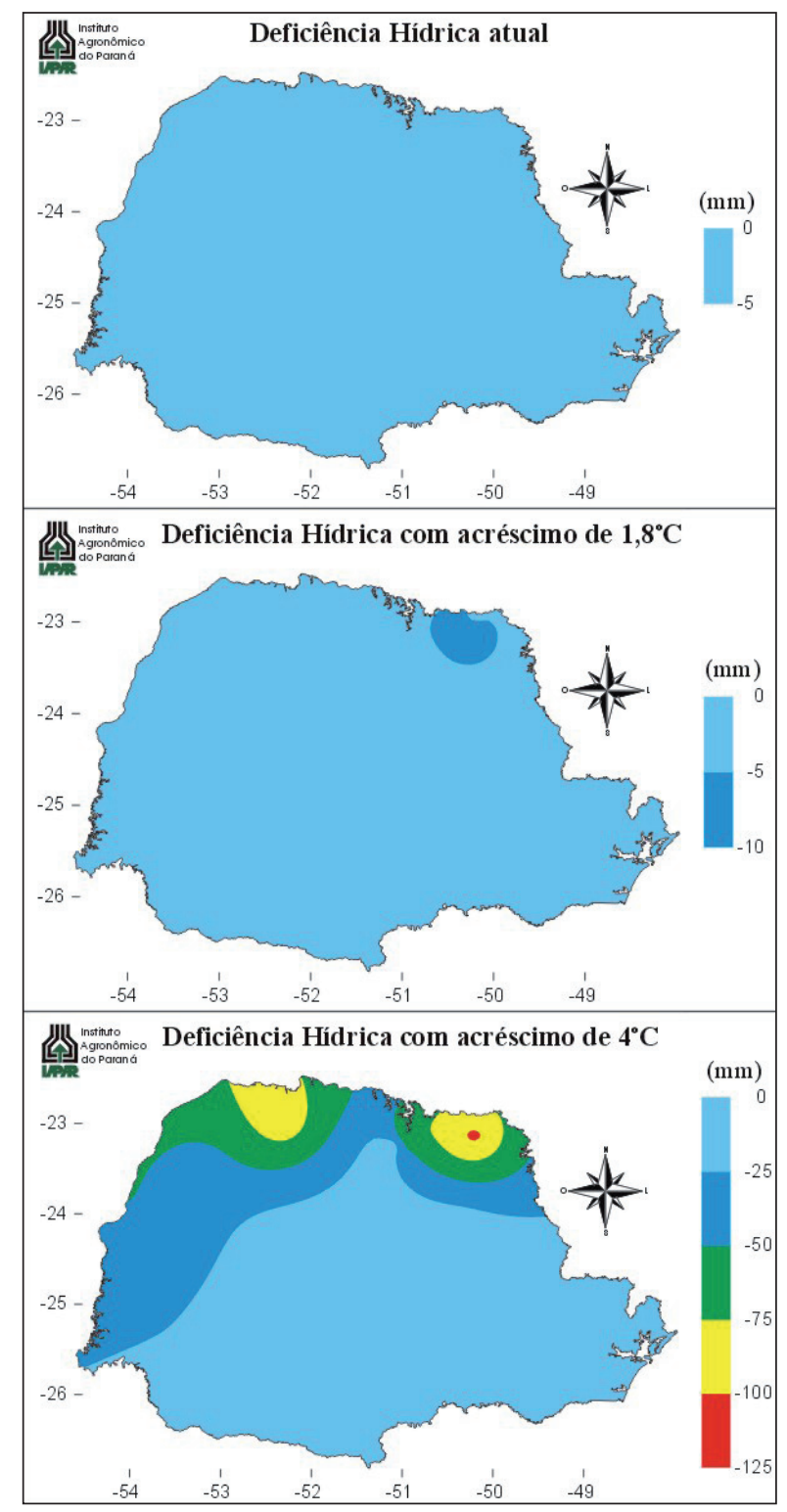

Fonte: Elaboração dos autores. 
Figura 2. Zoneamento de riscos climáticos da cultura do C. canephora para o estado do Paraná - cenário atual.

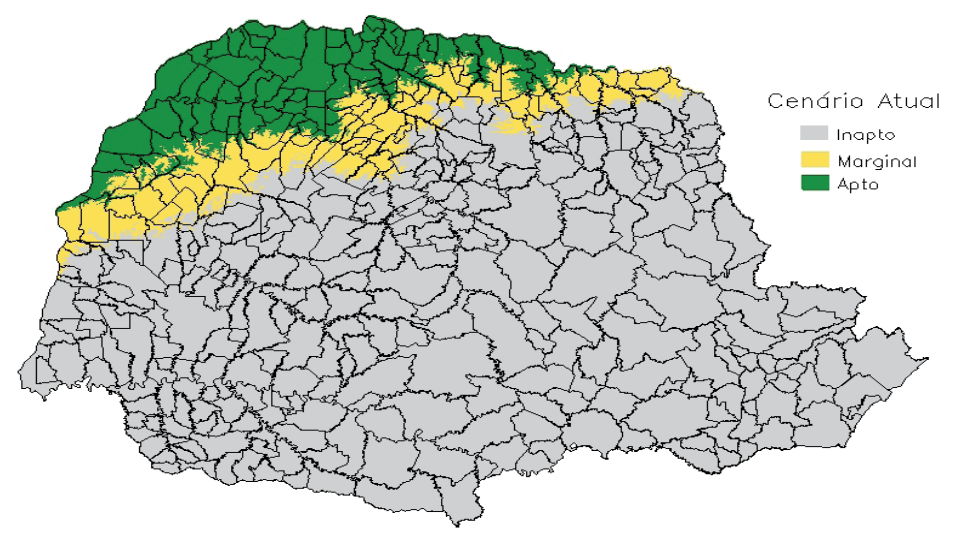

Fonte: Elaboração dos autores.

Figura 3. Temperatura média anual no estado do Paraná.

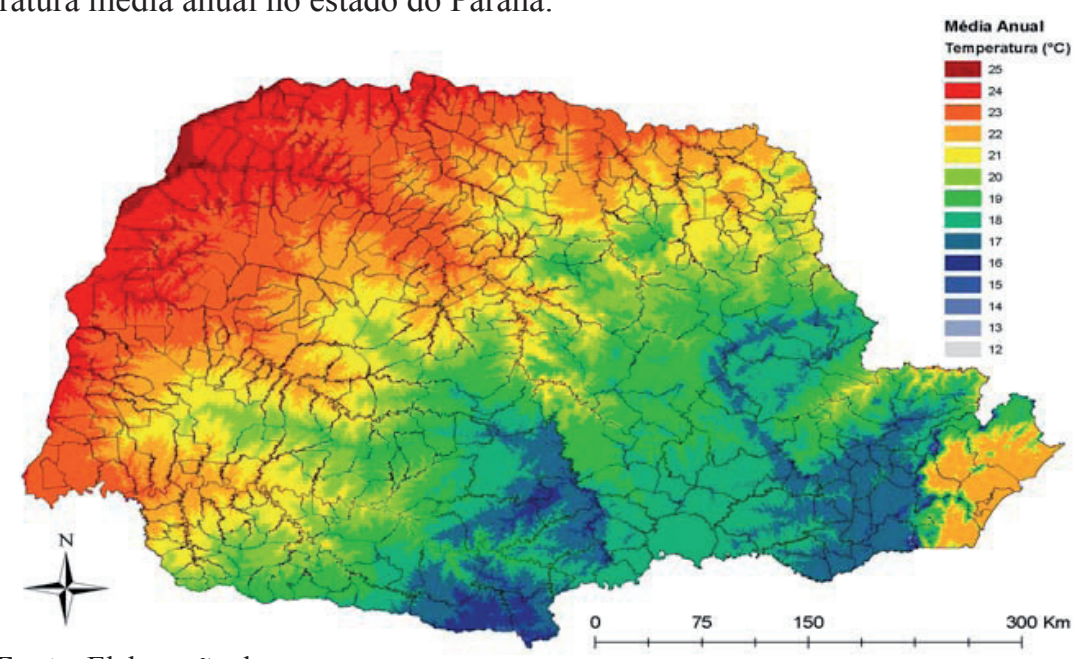

Fonte: Elaboração dos autores.

Figura 4. Risco de geada no estado do Paraná considerando temperaturas mínimas de abrigo inferiores a $1^{\circ} \mathrm{C}$.

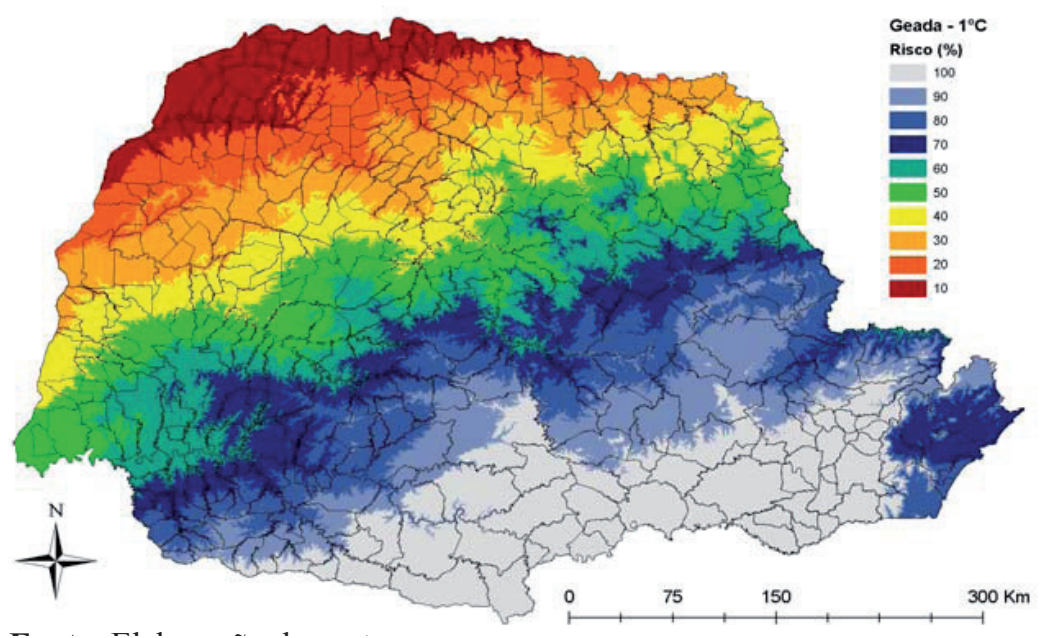

Fonte: Elaboração dos autores. 
Com o aumento de $1,8^{\circ} \mathrm{C}$ na temperatura média anual, valor atribuído ao cenário $\mathrm{B} 1$, conforme previsto pelo IPCC (2007), observa-se um aumento na área apta ao cultivo do café Robusta, que abrange praticamente toda a região noroeste, grande parte das regiões norte e oeste, e pequena parte da região central e litoral, mantendo-se inaptas as regiões mais frias do estado. A região litorânea, apesar de apresentar condições climáticas que a classificam como apta, não deve ser cultivada por se tratar de área de preservação ambiental (Figura 5). Assad et al. (2004), observaram que com o incremento de $1{ }^{\circ} \mathrm{C}$ na temperatura, ocorre um aumento na área apta para o cultivo de C. arabica no estado do Paraná, com deslocamento da área produtiva para o sul do Estado. Esse deslocamento se acentua com o aumento de $3{ }^{\circ} \mathrm{C}$, quando já é observada redução na área apta de $86,8 \%$ para $66,7 \%$ do estado.

Figura 5. Zoneamento de riscos climáticos da cultura do C. canephora para o estado do Paraná - cenário de aumento de $1,8^{\circ} \mathrm{C}$ na temperatura média anual.

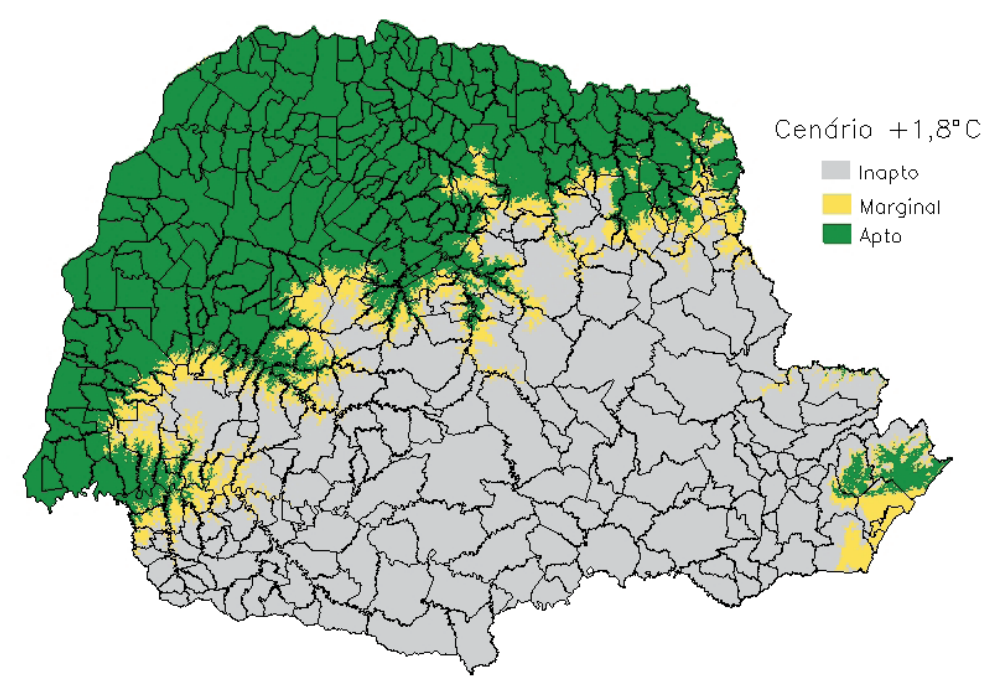

Fonte: Elaboração dos autores.

Com o aumento de $4^{\circ} \mathrm{C}$ na temperatura média anual cenário B1F1, previsto pelo IPCC (2007), o estado passa a ter novas regiões com restrições ao cultivo do café Robusta, neste caso devido às altas temperaturas (Figura 6). Nestas regiões o fator restritivo pode ser ajustado adotando-se técnicas de manejo, que poderão proporcionar aproveitamento melhor dos recursos naturais, tornando-as potencialmente produtivas (EVANGELISTA; CARVALHO; SEDIYAMA, 2002). Dentre essas práticas pode-se destacar o uso de espécies arbustivas e arbóreas consorciadas ao cafeeiro (CARAMORI et al., 2001). As áreas aptas se deslocariam para as regiões nordeste a sudoeste e parte da região leste. A região metropolitana de Curitiba e parte das regiões centro-sul e sul, continuariam inaptas devido às baixas temperaturas e a possibilidade de ocorrência de geadas.

Convém destacar que o presente estudo não considera as possíveis alterações nas ocorrências de eventos climáticos extremos, como secas, precipitações e outros, devido à dificuldade de quantificação e previsão desses eventos em estudos climatológicos de longo prazo como este. Não se considera também os avanços da pesquisa que poderão ocorrer nos próximos anos, os quais poderão mitigar muitos dos efeitos negativos decorrentes de um clima alterado. Os cenários 
apresentados constituem uma primeira aproximação do que poderá ocorrer caso se confirmem alterações climáticas nas proporções previstas, servindo como alerta para o estímulo de práticas que visem minimizar os impactos negativos e incentivar as pesquisas com técnicas de mitigação e avaliação de novas espécies.

Figura 6. Zoneamento de riscos climáticos da cultura do C. canephora para o estado do Paraná - cenário de aumento de $4^{\circ} \mathrm{C}$ na temperatura média anual.

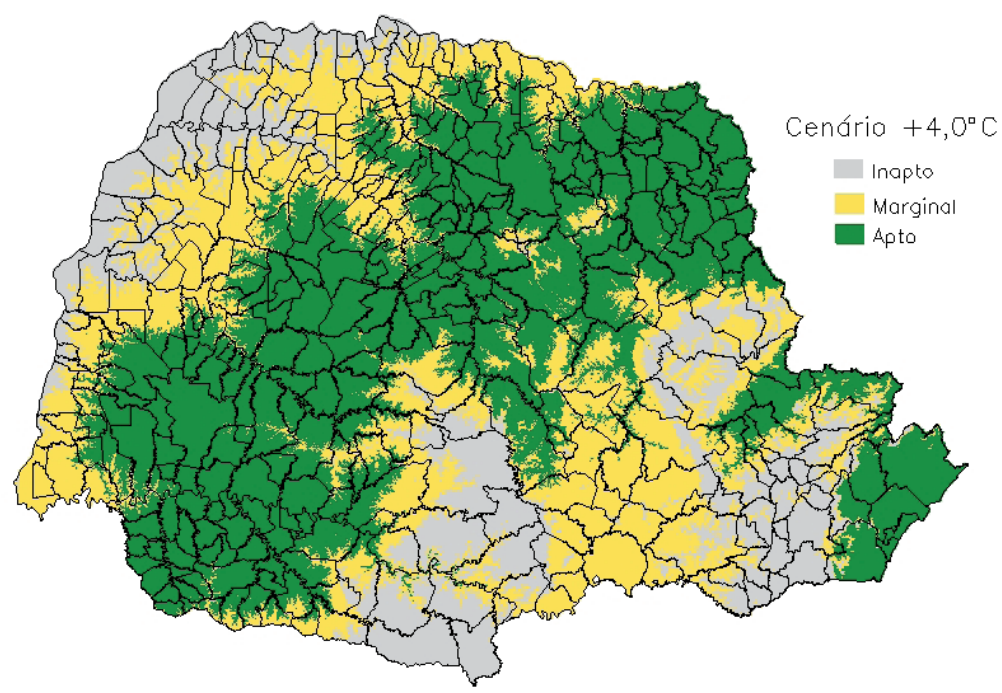

Fonte: Elaboração dos autores.

\section{Conclusão}

A espécie Coffea canephora tem potencial de cultivo na região noroeste e parte das regiões oeste e norte do Paraná nas condições atuais de clima. Caso se confirmem as previsões de aquecimento global, o potencial de cultivo do café robusta no estado se ampliará. Sob cenários de maior aquecimento, na região noroeste e em parte da oeste as temperaturas médias superam o tolerado pela espécie e passam a ser restritivas ao cultivo.

\section{Referências}

ASSAD, E. D.; PINTO, H. S.; ZULLO JUNIOR, J.; ÁVILA, A. H. Impacto das mudanças climáticas no zoneamento agroclimático do café no Brasil. Pesquisa Agropecuária Brasileira, Brasília, v. 39, n. 11, p. 1057 1064, 2004.
ASSIS, F. N.; ARRUDA, H. V.; PEREIRA, A. R. Aplicações de estatística à climatologia - teoria e prática. Pelotas: Universidade Federal de Pelotas, 1996. $161 \mathrm{p}$.

BLISKA, F. M. M.; PARREIRAS, S. P.; GIOMO, G. S.; VEGRO, C. L. R. Caracterização da produção de Coffea arabica e possibilidade de cultivo de Coffea canephora na região oeste do estado de São Paulo. Informações Econômicas, São Paulo, v. 38, n. 8, p. 38-42, ago. 2008.

CAMARGO, A. P. Zoneamento de aptidão climática para a cafeicultura de arábica e robusta no Brasil. In: Instituto Brasileiro de Geografia e Estatística. Recursos, meio ambiente e poluição. Rio de Janeiro, 1977. v. 1, p. 68-76.

CARAMORI, P. H.; CAVIGLIONE, J. H.; WREGE, M. S.; GONÇALVES, S. L.; FARIA, R. T.; ANDROCIOLI FILHO, A.; SERA, T.; CHAVES, J. C. D.; KOGUISHI, M. S. Zoneamento de riscos climáticos para a cultura de café (Coffea arabica L.) no Estado do Paraná. Revista Brasileira de Agrometeorologia, Santa Maria, v. 9, p. 486-494, 2001. Especial. 
CARAMORI, P. H.; MORAIS, H.; LEAL, A. C.; CARNEIRO FILHO, F.; MOREIRA, I. A. Avaliação de métodos de proteção contra geadas em cafezais recém implantados. In: SIMPÓSIO DE PESQUISA DOS CAFÉS DO BRASIL, 1., 2000, Poços de Caldas. Anais... Poços de Caldas, set. 2000. p. 30-33.

EVANGELISTA, A. W. P.; CARVALHO, L. G.; SEDIYAMA, G. C. Zoneamento climático associado ao potencial produtivo da cultura do café no Estado de Minas Gerais. Revista Brasileira de Engenharia Agrícola Ambiental, Campina Grande, v. 6, n. 3, p. 445-452, 2002.

GRODZKI, L.; CARAMORI, P. H.; BOOTSMA, A. Riscos de ocorrência de geada no estado do Paraná. Revista Brasileira de Agrometeorologia, Santa Maria, v. 4, n. 1, p. 93-99, 1996.

INTERGOVERNMENTAL PANEL ON CLIMATE CHANGE. Climate change 2001: working group II: impacts, adaptations and vulnerability. 2001. Disponível em: <http://www.grida.no/climate/ipcc_tar/wg2 /005. html>. Acesso em: 03 nov. 2007.

- Mudança do clima 2007: a base das ciências físicas. 2007. Disponível em: $<$ http://www.natbrasil. org. br/docs/ipcc_2007.pdf>. Acesso em: 03 nov. 2009.
MATIEllo, J. B. O café: do cultivo ao consumo. São Paulo: Globo, 1991. 319 p.

SANTOS, A. R. Zoneamento agroclimático para a cultura do café conilon (Coffea canephora Pierre ex Froehner) e arábica (Coffea arabica L.), na bacia do Rio Itapemirim, ES. 1999. Dissertação (Mestrado em Meteorologia Agrícola) - Universidade Federal de Viçosa, Viçosa.

THORNTHWAITE, C. W.; MATHER, J. R. The water balance. Centerton, Drexel Institute of TechnologyLaboratory of Climatology, 1955. 104 p. (Publications in Climatology, v.8, n. 1).

VESCOVE, H. V.; TURCO, J. E. P. Comparação de três métodos de estimativa da evapotranspiração de referência para a região de Araraquara - SP. Engenharia Agrícola, Jaboticabal, v. 25, n. 3, p. 713-721, 2005. 
